\title{
Third Generation Knowledge Management in Action: Relational Practices in Swiss Companies
}

\author{
Jens O. Meissner ${ }^{1}$ and Patricia Wolf ${ }^{2}$ \\ ${ }^{1}$ Lucerne School of Business, Switzerland, jens.meissner@hslu.ch \\ ${ }^{2}$ ETH Zurich, Switzerland, pwolf@ethz.ch
}

\begin{abstract}
This paper aims at answering the question: How do "third generation knowledge management concepts" help to understand relational practices in blended contexts of face-to-face interaction and virtual communication? In order to address this question, we firstly explain Scharmer's Concept of Self-transcending Knowledge and Snowden's Knowledge-Ecology-Approach 'Cynefin' to develop a heuristic for third generation knowledge management (KM). The heuristic highlights the critical role of relational practices for KM and will be applied to identify and discuss selected relational practices stemming from four Swiss organizations. We conclude by reflecting on the adequateness of third generation knowledge management concepts to explain these practices.
\end{abstract}

Keywords: Third generation knowledge management, Relational practices, Hybrid work settings

\section{Introduction}

The motivation of this paper results out of two basic trends that challenge today's organizational KM practices: The first is the pervasiveness of virtual communication which is enhanced by ubiquitous computerization and advanced networking technology (Dutta \& Mia, 2007). The second is the ongoing unfolding of knowledge society that still seems to be in an early stage of its development (e.g. Castells, 2001).

It has been shown that cooperation and collaboration in organizations often have to be mastered in neither entirely co-located nor entirely distributed work settings. Instead, organization's members have to manage their actions in hybrid settings in which face-to-face interactions and virtual communications are blended together (Griffith, Sawyer \& Neale, 2003). In this environment, all the involved 
actors work and communicate with a specific mix of communicative practices that consist of face-to-face and computer-mediated interaction (Zachry \& Thralls, 2006). For being effective, KM approaches have to be aware of these rich situational conditions in organizations. The guiding question that we are going to answer in this paper is: How do "third generation knowledge management concepts" help to understand relational practices in blended organizational contexts of faceto-face interaction and virtual communication?

To answer this question, we firstly develop a third generation knowledge management heuristic which is based on two well-known concepts. We rely upon epistemological roots of Newer Sociological Systems Theory (Luhmann, 1995), knowledge sociology (Berger \& Luckmann, 1966) and relational constructivism (Gergen, 2001). Our basic assumption is that organizations consist mainly of communicative routines. From this background, Weick's concept of the "double interact" (Weick, 1995) plays a crucial integrating role between relationships and organizations. Secondly, we apply the heuristic to analyze selected relational practices we uncovered during our research in Swiss organizations.

\section{Third Generation Knowledge Management}

Third generation KM approaches were developed approximately ten years ago. While first-generation KM concepts treated knowledge as a thing, secondgeneration concepts understood knowledge as a process which is partially explicit and implicit (Nonaka \& Takeuchi, 1995). The third generation KM approach focuses also on implicit knowledge but purposefully deals with the function of knowledge ecology, chaos and the sensing of opportunities-to-come. Knowledge in this approach is also tacit but it is 'not embodied yet' and has to be generated (Scharmer, 2001). From a knowledge management perspective, third generation concepts base on the assumption of knowledge as an "ephemeral, active process of relating" (Stacey, 2001) thus highlighting the process of "knowing" instead of conceiving knowledge as an objective entity.

Third generation KM concepts highlight the relevance of chaos, complexity and paradox and frame them as critical KM resources. This can lead to a challenge for 'traditional' KM experts who are interested in an object-like understanding of knowledge and who usually try to make knowledge transferable, manageable and teachable. We will not contribute to this positivistic understanding of KM. Instead, we will develop a general "Third Generation KM Heuristic" and provide insights from an empirical set of qualitative data on relational practices in Swiss companies. For the development of the heuristic, two particular relevant approaches will be described in the next sections: Scharmer's Concept of Self-transcending Knowledge (2001) and Snowden's Knowledge-EcologyModel 'Cynefin’ (2002). 


\subsection{Scharmer's Concept of Self-transcending Knowledge}

Claus-Otto Scharmer refers to Polanyi's (1967) distinction between explicit and tacit-embodied knowledge and advances this understanding by adding a third type of knowledge that is "self-transcending" (Scharmer, 2001). This latter type of knowledge is characterized as knowledge that is "not-yet-embodied" which is a source for leaders to sense, actualize and engage in emerging business opportunities. The concept is tightly bound to personal awareness and psychological presence and thus can be found as a crucial resource for entrepreneurial thinking (Scharmer, 2007).

The three types of knowledge can be traced back to different epistemological assumptions (Scharmer, 2001:143ff). Explicit knowledge refers to know-how and to know-what. It's knowledge about things that can be found within an external reality. We can explore it, detect it, construct it, store it in databanks and IT systems and so on. Within this type of knowledge the separation between the knower and the known is constitutive. Implicit knowledge is a living process and can be understood as knowledge-in-use. As such, it is knowledge about doing things and can be experienced within action settings. This knowledge becomes very visible in master craftsmanship but also knowledge processing within communities of all kind. Self-transcending knowledge goes one step ahead to pre-sensing (Senge et al., 2005 call it "presencing") reality. It can be understood as reflection-in-action and knowing about thought-origins for doing things (Scharmer, 2001:143). The domain of self-transcending knowledge is the field of intuition, inspiration and imagination. Many entrepreneurs and leaders - especially those who are refered to as "charismatic" - are able to perform with virtuosity within this domain.

Obviously, the three types of knowledge are very different in character and each type requires a different type of knowledge environment and learning infrastructure. Crucial, from Scharmer's perspective, is the spiral of creating selftranscending knowledge within the interplay between the organizational commonalities 'shared praxis', 'shared reflection' and 'shared will': "The more distributed organizations and networks of collaboration become, the more critical [learning infrastructures for self-transcending knowledge] tend to be, because shared praxis, shared reflection, and formation of shared will are the glue that keeps distributed networks in synch and together." (Scharmer, 2001:147). Thus, the main KM challenge lies within the turning of distributed labour into shared experience, abstract discussions into shared reflection and negotiation of objectives into the formation of collective will (Scharmer, 2001:148).

Scharmer concludes that "requisite conversational complexity" will need different forms of conversation to sustain diverse forms of knowledge. The most relevant form (and infrastructure) to successfully handle self-transcending knowledge is 'generative dialogue'. Most KM systems fail in this because they fail in establishing the necessary conversational complexity for this form of dialogue. This failure has significant consequences: "Without the capacity for dialogue, for ins- 
tance, teams are unable to express their tacit, taken-for-granted assumptions about how reality works" (Scharmer, 2001:22).

For our purposes, Scharmer's concept enables us to ask some interesting questions concerning KM in organizations, for example: Where can we find modes and places of presencing? How and why is requisite conversational complexity created and accepted? And, which pre-conditions have to be fulfilled to enable generative dialogues (and to stay in them despite of the guaranteed upcoming impertinencies)?

\subsection{Snowden's Knowledge-Ecology-Approach 'Cynefin'}

The second third generation KM approach to be outlined here was developed by David Snowden (2002). His concept focuses on organizational knowledge ecology and became known as the "Cynefin"-model. It highlights the capacity of an organization to create just-in-time KM as well as disruptive innovation. It bases on the contextuality of knowledge in which the degree of abstraction and cultural dependence play a critical role in managing it: "In the third generation we grow beyond managing knowledge as a thing to also managing knowledge as a flow. To do this we will need to focus more on context and narrative, than on content" (Snowden, 2002:101).

Whereas Scharmer conceptualizes third generation knowledge beyond the process scope, Snowden stays within this category. But, Snowden emphasizes the contextuality of knowledge - and thus stays close to the idea of knowledge as a flow. Towards knowledge ecology, its context and its embeddedness into narratives have to be taken into account. Snowden states, that human knowledge is deeply contextual and triggered by circumstance: "In understanding what people know we have to recreate the context of their knowing if we are to ask a meaningful question or enable knowledge use. To ask someone what he or she knows is to ask a meaningless question in a meaningless context" (Snowden, 2002:102). Therefore, KM needs the clear distinction of content, context and narrative to be managed adequately - Cynefin focuses more on the latter two, less on the content.

The Cynefin model is segmented into four knowledge domains (see Figure 1): The domain of bureaucratic and structured knowledge is the formal organization consisting of policies, procedures and controls. The language within this domain is known and explicit. Within the professional and logical domain, a high abstraction level of knowledge is possible. Typical knowledge artefacts are e.g. textbooks which usually contain codified terminologies of specialists (Snowden, 2002:104). In the informal and independent domain, the trust in social networks plays an important role. Learning, shared values and beliefs, and the making of shared experiences belong. Last, the uncharted and innovative domain comprises temporary, often spontaneous communities for the generation of new knowledge and disruptive innovation. "Each of the domains contains a different model of community 
behaviour; each requires a different form of management and a different leadership style" (Snowden, 2002:106).

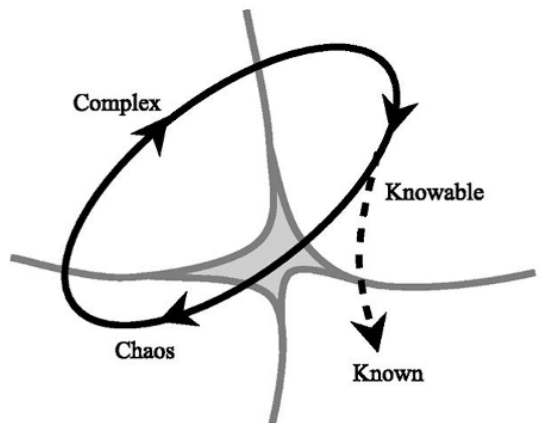

Figure 1. Cynefin: Knowledge flows (Snowden, 2001:108)

The Cynefin model signifies two critical knowledge transitions: Firstly, the shift from complex to knowable knowledge for sustaining "Just-in-time" knowledge. Secondly, knowledge that is trespassing from the knowable to the chaotic sphere to radically question existing knowledge and to achieve knowledge innovation.

For our purposes Snowden's concept provides us with some important questions, as there are: What kinds of contexts arise within hybrid work settings in organizations? What kinds of narratives are stipulated? And how do they affect relational practices?

\subsection{A Third Generation Knowledge Management Heuristic}

Theoretically informed by the both concepts, we can now define a guiding third generation KM heuristic. Scharmer's concept highlights the emergence of selftranscending knowledge and the need to presence it - i.e. to reflect on it (Scharmer, 2001). He states the requirement of a requisite conversational complexity for sustaining all types of knowledge. He proposes the generative dialogue as an adequate "technique" especially for maintaining and dealing with third generation knowledge. Snowden emphasises the capacity of an organization to create just-in-time knowledge as well as disruptive innovation. He argues an ecological understanding of knowledge and identifies four domains with different rationalities that serve as order criteria for knowledge. Snowden delineates two critical transitions to address the two main problems for knowledge transformation: From 'complex' to 'knowable' and from 'known' to 'chaotic'. Both transitions radically question the rationality and functionality of existing knowledge in organizations. The insights of both third generation KM models are shown in Table 1. 
Table 1: Third Generation Knowledge Management Heuristic.

\begin{tabular}{|c|c|c|c|}
\hline & $\begin{array}{l}\text { Self-transcending } \\
\text { Knowledge Model } \\
\text { (Scharmer, 2001) }\end{array}$ & $\begin{array}{c}\text { Knowledge } \\
\text { Ecology Model } \\
\text { (Snowden, 2002) }\end{array}$ & $\begin{array}{c}\text { Analytical } \\
\text { question for relational } \\
\text { practices }\end{array}$ \\
\hline $\begin{array}{l}\text { Knowledge } \\
\text { Source }\end{array}$ & $\begin{array}{c}\text { Presencing } \\
\text { (reflection-in-action) }\end{array}$ & $\begin{array}{c}\text { Contextual } \\
\text { (ecological, bound in } \\
\text { narratives) }\end{array}$ & $\begin{array}{c}\text { Does it enable presencing } \\
\text { and (re) contextualizing } \\
\text { of knowledge? }\end{array}$ \\
\hline $\begin{array}{l}\text { Knowledge } \\
\text { Order }\end{array}$ & $\begin{array}{c}\text { Requisite } \\
\text { conversational } \\
\text { complexity } \\
\text { (heterogeneity) }\end{array}$ & $\begin{array}{c}\text { Different rationalities } \\
\text { and languages } \\
\text { (domains of knowledge) }\end{array}$ & $\begin{array}{c}\text { Does it contribute to } \\
\text { requisite conversational } \\
\text { complexity? }\end{array}$ \\
\hline $\begin{array}{l}\text { Knowledge } \\
\text { Management } \\
\text { Challenge }\end{array}$ & $\begin{array}{l}\text { Generative dialogue } \\
\text { (enabling mind shifts) }\end{array}$ & $\begin{array}{c}\text { Critical transitions } \\
\text { (Just-in-time, disruptive } \\
\text { innovation) }\end{array}$ & $\begin{array}{l}\text { Does it foster the } \\
\text { emergence of } \\
\text { generative dialogue? }\end{array}$ \\
\hline
\end{tabular}

To bring out the impacts for third generation KM, we can now subsume the results by asking: How is knowledge sourced, ordered and managed within relational practices? Focusing on relational practices we can ask three analytical questions: Does the respective practice

- enable presencing and (re)contextualizing of knowledge?

- contribute to requisite conversational complexity, opens up for different rationalities and languages, which is increasing the "knowledge variety"?

- foster the emergence of generative dialogue and of critical transitions, which we name as increasing "knowledge conversion"?

The three questions of the heuristic signify the three dimensions of third generation KM which subsequently serve the systematic assessment of the following selected relational practices in Swiss organisations.

\section{Selected Knowledge Practices in Swiss Organizations}

In this section we describe our research design as well as the relational practices that we were able to identify in Swiss organizations. The practices will be analyzed with the third generation KM heuristic. 


\subsection{Research Design}

Our research followed a social constructionist rationale, which assumes that reality is a product stemming from social relationships (Gergen, 2001, Dachler \& Hosking, 1995). This perspective on relationships implies that our research had to focus on relationships and topics that might be highlighted in stories about relationships. Thus we had to gather insights about knowledge processes by trying to "look through the eyes of the other" (Bryman, 1988).

We selected interviewees from four service and knowledge-intense companies in order to assure a certain degree of contextual diversity in the sample. The first company was a services department of a document imaging service provider that relies heavily on its project organization. As a second organization, the holding of a financial services company was chosen. The third organisation was the global headquater of a multi-national pharmaceutical company. As a fourth organization we selected the national branch of a multinational stategy expert consultancy with more than hundred employees in Switzerland and several thousands world-wide. All companies are located in the German-speaking part of Switzerland.

In each organization, four to seven interviews were conducted between late 2004 and April 2005. Interview partners were selected in cooperation with one "gatekeeper" who was appointed by leaders in upper or top management (leader of the staff division/assistant of the CEO/the site leader/managing partner). The selected interviewees had to fulfill two minimum requirements: Firstly, they should have access to a variety of five or more distinguishable communication technologies in their working context - for example phone, mail, webconferencing, videoconferencing, shared databases or platforms, mobile phone and/or mail, etc. Secondly, their everyday work life should be predominantly related to communication activities. Overall, the whole sample consists of 21 interviewees, working in aidee and management positions to the largest part.

We chose a problem-centered narrative interview approach (Witzel, 2000) to generate stories. While the pure narrative interview demands the researcher to reduce his own influences to a minimum, the problem-centered interview focuses on generating meaningful sequences. Each interview began with the question "When you reflect upon your daily communications, what comes into your mind?", took about one to one and a half hours and was transcribed verbatim.

Throughout the subsequent analysis all participating researchers were guided by the following questions: How does the narrator see relationships in his context and what qualities does this construction offer? The main advantage of this method (compared with other well-known content analysis techniques like those used by Glaser and Strauss (1967), for example) is that there is no pre-formulated coding scheme which could be used. The coding scheme emerged out of the issues and topics that were adressed by the narrator himself.

For the validation of the analysis we advanced in two steps: The first step was to compare our own analysis with that of another researcher, who also analyzed it. 
During this step the interpreted topics and the landscape were critically discussed, reviewed and validated in multiple sessions (see Meissner, 2007 for a detailed description of this process). In a second step, the results were validated with the interviewee him or herself. In the end, the aggregation of topics from multiple organizational members enabled the researcher to identify typical common traits (communicative practices) of the organization. The analysis resulted in a list of topics and quotations from all interviews. Each interview was illustrated with a thematic map (the "landscape") which displayed the specific topics and their relations to each other. Also, a landscape over the whole sample was developed.

Overall we found eight typical relational practices. These can be subsumed under the categories "contextualization of the message content", "shaping relationships", "technological enabling of communication" and the "social construction of technology by human communication". These four categories stem from the "relational scaffolding model" provided by Meissner \& Tuckermann (2007). As the section serves as illustration for the explanatory power of the third generation KM heuristic, only two of the categories are investigated in more depth. We focus on the categories "Contextualization of message content" and "Shaping Relationships", both comprising two typical relational practices.

\subsection{Contextualization of Message Content}

The practices people placements and awareness of social spheres can be seen as measures to enact a specific context for technologically mediated messages.

Especially in the second organization, people placements took care for an efficient and holistic information transfer between organization and client. This means, that within client projects at least one employee of the organization was located at the site of the customer to get in touch with the culture and the work atmosphere. That way it was possible to 'translate' the clients problems in the organizations' language. One project leader described a situation in which a project faced severe problems. Instantly, the project leader took the next flight to the customer's site. Originally, it was not his project and he was not involved - but somehow he was the only one at-hand. He remembers:

"For the customer this really had a calmative effect: 'Ah, someone else is coming to help us here to solve the problem. That's a new face... someone who is reliable.' This was an enormous help. You cannot get such an effect by video conferences or anything technical. By the way, in this sense there is no difference between web conferences and even telephone conferences. Conferencing just doesn't contribute to trust building. That's our experience at least."

By people placements, the organization adds a pre-existing relationship (between the core team of the organization and distributed members) to the otherwise solely message-centered information exchange. Organisations can build other relationships around the secured connection. 
Awareness of social spheres directs towards the increased attention of the employees to maintain places and times for face-to-face meetings in which the social contact is consciously nurtured. Within these interaction spaces people appreciate the socially rich context. Especially the informal coffee breaks have a social value on their own which can become relevant for conducting business as it allows for personal relationships to build across the departmental "garden fences":

"We care for this interaction but they are not formal settings - they are informal talks. But we do care for business issues, too. Well, it's a platform where we meet once or twice a day. One comes along the floor [he is pointing on the open door] - 'Coffee!' and then we know now comes a phase of relaxation and to talk about things beyond the garden fence. We can deal with private issues - 'my cat's sickness' and such things. And I think, that is very important."

Employees use these interaction spaces as social contexts where they can validate or improve virtual messages which were sent afore. Thus, they can verify and improve the creation of shared meaning that was intended by prior virtual communication activities. To realize this practice, organizational members need to have niches of physical presence where conversation with a high degree of synchronicity is possible, e.g. coffee breaks and water cooler talks.

Both practices serve to backup virtual messages with relational information and to contextualize them in this way.

\subsection{Shaping Relationships}

Committing on ground rules and also communication code of conduct are two practices that serve the shaping of relationships. In both practices the norms of how to behave in virtual communication are explicitly discussed.

By generating commitment to ground rules of communication relational issues within virtual teamwork are acknowledged that would otherwise be ignored. A HR manager explained:

"[There are] simply certain physical limitations, how much you can realize the personal gettogether. As a leader you have to possibilities: Either you pull all people together or you visit them at the site. For virutal work this means that other rules have to be defined. We named them "groundrules". For example, we imposed on us different groundrules depending on whether we work with video conferencing, NetMeeting or shareweb. Especially the rules have to be changed about how we deal with these issues in interpersonal communication."

The central challenge lies in the use of communication technology in a way that it's no barrier to efficient work. People have to try to discipline themselves in virtual communication but are not really successful in developing collective routines that foster this striving. The use of video conferencing is such a part of mutual disciplining in virtual communication because this type of communication cannot be that inflationary used like e-mails can.

A strongly shared communication code of conduct makes it easier to effectively communicate via communication media especially within an organizational setting 
consisting of project oriented teams. By knowing the explicitly concerted communication code of conduct, the project members can build expectations about each others' communication behaviour. In most companies there seems to exist a wide agreement upon the standard how reachable the project team members have to be. A project member states:

"A manager of us is actually reachable. He cannot say 'good bye' and go into vacation. Maybe reluctantly, but you'll reach him somehow. He will check his voice mail and reply. Whereas an a project associate: If he goes in vacation, he really will be in vacation. It's very seldom that someone calls him there or leaves him a voice mail message."

The communication code of conduct is a part of the organization's memory and contains a pre-understanding about the nature of the work, the importance of communication and the expectations regading the reachability within the company. The code of conduct reduces uncertainty and prevents circumstantial coordination (who is how when and why reachable). Without this mutual understanding, the coordination efforts for simple regular day-to-day collaborations would be prohibitive high.

These two practices in this category point towards the shaping of relationships by explicitly communicating the norms of how to behave in hybrid communication.

\subsection{Applying the Third Generation KM Heuristic}

We now can use the developed KM heuristic to analyze the relational practices regarding their implications for third generation KM (see Table 2).

Table 2: The Third Generation KM Heuristic and identified relational practices.

Does it enable
presencing and $\begin{gathered}\text { Does it contribute to Does it foster the } \\ \text { (re)contextualizing } \\ \text { of knowledge? }\end{gathered}$ tional complexity? erative dialogue?

\begin{tabular}{cccc}
\hline People placements & $\begin{array}{c}\text { Brings new people } \\
\text { in the organization } \\
\text { and creates a new } \\
\text { context. }\end{array}$ & $\begin{array}{c}\text { Brings new people } \\
\text { in the organization } \\
\text { and creates new } \\
\text { knowledge. }\end{array}$ & $\begin{array}{c}\text { Brings new people } \\
\text { to lead a dialogue } \\
\text { with. }\end{array}$ \\
$\begin{array}{c}\text { Contributes to the } \\
\text { Awareness of } \\
\text { emecial spheres }\end{array}$ & $\begin{array}{c}\text { Contributes to the } \\
\text { spaces for new } \\
\text { contexts. }\end{array}$ & $\begin{array}{c}\text { Contributes to the } \\
\text { spaces for new } \\
\text { knowledge. }\end{array}$ & $\begin{array}{c}\text { cmergence of new } \\
\text { spaces to lead a } \\
\text { dialogue in. }\end{array}$ \\
\hline
\end{tabular}




\begin{tabular}{lccc}
\hline $\begin{array}{c}\text { Committing on } \\
\text { ground rules }\end{array}$ & $\begin{array}{c}\text { Contributes to a } \\
\text { shared context to } \\
\text { generate new } \\
\text { knowledge. }\end{array}$ & $\begin{array}{c}\text { Contributes to a } \\
\text { shared context to } \\
\text { make complex } \\
\text { issues knowable. }\end{array}$ & $\begin{array}{c}\text { Contributes to a } \\
\text { shared context } \\
\text { between the people } \\
\text { involved. }\end{array}$ \\
$\begin{array}{c}\text { Contributes to a } \\
\text { communication }\end{array}$ & $\begin{array}{c}\text { Contributes to a } \\
\text { shared language to } \\
\text { make complex } \\
\text { shared language to } \\
\text { issues discussable. }\end{array}$ & $\begin{array}{c}\text { Contributes to a } \\
\text { knowledge. }\end{array}$ & $\begin{array}{c}\text { shared language } \\
\text { between the people } \\
\text { involved. }\end{array}$ \\
\hline
\end{tabular}

As can be seen, the heuristic offers interesting contributions of the practices to characterize their effect regarding the three dimensions of third generation KM.

In a second step, it would now be possible to reflect more deeply on each field of the table. For example, the communication code of conduct contributes to a shared language to make complex issues discussable. Therefore, presencing is supported by the relational practice. At the same time, the code prevents this presencing because it goes hand in hand with a kind of standardization within the organization: When a code of conduct exists, the degree of mutual reachability is (more or less) expectable. For presencing (that is reflection-in-action, spoken with Scharmer), exactly the opposite could be a better choice.

As can be seen here, further inverstigations could be induced here. The heuristic's aim is to systematically raise such questions and entry-points for discussions. Thus, the value-added of the heuristic lies within its systematic and comprehensible approach to reflect upon existing communication practices.

\section{Conclusion}

At the beginning of this paper, the research question was: How do "third generation knowledge management concepts" help to understand relational practices in blended contexts of face-to-face interaction and virtual communication? We used third generation KM approaches as a focus lens to identify crucial aspects of KM in organizations. Then, we described relational practices in hybrid work settings and applied the third generation KM heuristic to identify the effect of the relational practices on third generation KM. The usefulness of the third generation KM heuristic became apparent when we used it as a helpful lens to analyze relational practices in the studied organizations. However, it was mentioned, that the heuristic is to be understood as a vehicle to reflect upon existing communication practices. Therefore, it is not a tool to assess whether a practice is good or bad per se.

The results show that analysis benefits from qualitative research heuristics like the one we elaborated here. Heuristics as conceptual frameworks are still hard to 
find although qualitative approaches of organizational studies clearly left infancy behind. Especially, theory has to encourage the study of situational rich contexts like hybrid work settings. Hybrid contexts become the normal case - but they are more difficult to be accessed and researched than experimental designs are.

For the overarching theory of organizational communication the findings indicate, that existing concepts base upon too linear and static models trying to satisfy quantitative pressure upon the discipline. We assume that it's the rationality of the organization that decides which modes of communication are acceptable and which composition of relational practices within hybrid work settings is adequate to serve the organization's aims. Against the background of this essay, organizational communication as an academic discipline would be well advised to invest some time in studying sociologically informed communication theory and to combine it with organizational perspective. The Newer Social Systems Theory (Baecker, 2007; Luhmann, 1995) would be a valuable resource for this.

Acknowledgements: The authors would like to acknowledge the support of the WWZ-Forum at the University of Basel (research project number "D-90: Social capital in digital context?"). The authors especially thank the interview participants for allowing us access to their work lives and personal perspectives. An earlier draft of this paper was presented at the 23nd EGOS colloquium 2007 in Vienna.

\section{References}

Baecker, D.: Communication With Computers, or How Next Society Calls for an Understanding of Form. Soziale Systeme, 13(1/2) (2007).

Berger, P. L. \& Luckmann, T.: The Social Construction of Reality: A Treatise in the Sociology of Knowledge. Garden City, Doubleday, New York (1966).

Bleicher, J.: Contemporary Hermeneutics: Hermeneutics as Method, Philosophy and Critique. Routledge \& Kegan Paul, London and Boston (1980).

Bryman, A.: Quantity and Quality in Social Research. Unwin Hyman, London (1988).

Castells, M.: The Internet Galaxy. Reflections on Internet, Business, and Society. Oxford University Press (2001).

Dachler, H. P. \& Hosking, D.-M.: The Primacy of Relations in Socially Constructing Organizational Realities. In D.-M. Hosking, H. P. Dachler \& K. J. Gergen (Eds.), Management and Organizations: Relational Alternatives to Individualism. Avebury, Aldershot, 1-28 (1995).

Dutta, S. \& Mia, I.: Global Information Technology Report 2006-2007: Connecting to the Networked Economy. Palgrave Macmillan (2007).

Gergen, K. J.: Social Construction in Context. Thousand Oaks, CA. Sage (2001).

Glaser, B. G. \& Strauss, A. L.: The discovery of grounded theory. Strategies for qualitative research. De Gruyter, New York: (1967).

Griffith, T. L., Sawyer, J. E. \& Neale, M. A.: Virtualness and knowledge in teams: Managing the love triangle of organizations, individuals, and information technology. MIS Quarterly, 27(2). 265-287 (2003).

Luhmann, N.: Social systems. Stanford University Press, Stanford, CA (1995). 
Meissner, J. O.: Multi-stage analysis for knowledge reflection. In: A. S. Kazi \& P. Wolf (Eds.): Hands-On Knowledge Co-Creation and Sharing: Practical Methods and Techniques. Knowledge Board. 291-307 (2007).

Meissner, J. O. \& Tuckermann, H.: A Relational Scaffolding Model of Hybrid Communication. In: C. Steinfield, B. Pentland, M. Ackerman \& N. Contractor (Eds.): Proceedings of the Communities and Technologies 2007, Michigan State University. Springer, London, 479-508 (2007).

Nonaka, I. \& Takeuchi, H.: The Knowledge-Creating Company. Oxford University Press, New York (1995).

Polanyi, M.: The Tacit Dimension. Routledge \& Kegan, London (1967).

Scharmer, C.-O.: Self-transcending knowledge: Sensing and organizing around emerging opportunities. Journal of Knowledge Management, 5(2), 137-151 (2001).

Scharmer, C. O.: Theory U: Leading from the Future as it Emerges. Society for Organizational Learning (2007).

Senge, P., Scharmer, C. O., Jaworski, J. \& Flowers, B. S.: Presence: An Exploration of Profound Change in People, Organizations, and Society. Currency, New York (2005).

Snowden, D.: Complex acts of knowing: paradox and descriptive self-awareness. Journal of Knowledge Management, 6(2), 100-111 (2002).

Stacey, R.: Complex Responsive Processes in Organizations: Learning and Knowledge Creation. Routledge, London. (2001).

Weick, K. E.: Sensemaking in organizations. Sage, Thousand Oaks, CA. (1995).

Witzel, A.: The Problem-Centered Interview. Forum: Qualitative Social Research, 1(1), (2000).

Zachry, M. \& Thralls, C. (Eds.): Communicative Practices in Workplaces and the Professions: Cultural Perspectives on the Regulation of Discourse and Organizations. Baywood Publishing, Amityville, NY (2006). 